\title{
Potential prescribing omissions of medications in older adults based on START version 2 criteria in a tertiary Jordanian teaching hospital
}

\author{
Khawla Abu Hammour ${ }^{1 *}$, Mariam Abdeljalili1, Rana Abu Farha², Sara Alhabeis ${ }^{3}$, Qusai Manaseer ${ }^{4}$, Samah AbuMoghli ${ }^{1}$ \\ ${ }^{1}$ Department of Biopharmaceutics and Clinical Pharmacy, Faculty of Pharmacy, University of Jordan, Amman, Jordan. \\ ${ }^{2}$ Department of Clinical Pharmacy and Therapeutics, Faculty of Pharmacy, Applied Science Private University, Amman, Jordan. \\ ${ }^{3}$ Clinical Pharmacist, Al-Balqa' Applied University, Salt, Jordan. \\ ${ }^{4}$ Faculty of Medicine, University of Jordan, Amman, Jordan.
}

\begin{tabular}{l}
\hline ARTICLE INFO \\
\hline Received on: $10 / 06 / 2021$ \\
Accepted on: $12 / 08 / 2021$ \\
Available Online: $03 / 11 / 2021$ \\
\\
\hline Key words: \\
Prescribing omission, older \\
adults, acute illness, START \\
screening tool.
\end{tabular}

\section{INTRODUCTION}

Altering medications is the most common health intervention in modern healthcare systems (NICE, 2015). Hospitalized patients worldwide are prone to many threats that may impose actual harm to their health, one of them being the act of inappropriately prescribing medications (Cheragi et al., 2013;

${ }^{*}$ Corresponding Author

Khawla Abu Hammour, Department of Biopharmaceutics and Clinical Pharmacy, Faculty of Pharmacy, University of Jordan, Amman, Jordan. E-mail:k.hammour@ju.edu.jo

\begin{abstract}
Potential prescribing omission (PPO) represents a failure in prescribing drugs when indicated due to lack of the evidence base. Published data are scarce on the prevalence of prescribing omissions in Jordan. This study aimed to assess the prevalence of prescribing omissions in elderly patients in a Jordanian teaching hospital. Screening Tool to Alert doctors to the Right Treatment (START) version 2 was used to identify the prescribing omissions in older adults admitted to a tertiary hospital in Jordan for 18 months. During the study period, data relating to the patients' medical problems and prescribed medicines were collected by two clinical pharmacists via reviewing the clinical and prescription records of the included patients. Data were collected using a predefined data collection form and statistical analysis was conducted using Statistical Package of Social Sciences (SPPSS). One or more prescribing omissions were found in $40.5 \%, 41.0 \%$, and $39.5 \%$ of the patients upon admission, during hospitalization, and on discharge, respectively. The most common prescribing omission was about START criterion I1 which was "seasonal trivalent influenza vaccine annually" in 54.8\% upon admission, $51.5 \%$ during hospitalization, and $51.9 \%$ on discharge. Logistic regression found that the higher number of medical conditions was associated with an increased risk of PPO occurrence upon admission, during hospitalization, and on discharge ( $p$ value $<0.05$ ). Acts of omission of appropriate medications were highly prevalent among older patients in our hospital setting. A validated screening tool (START) is one method of systematically identifying appropriate omitted medicines in clinical practice. Application of validated START criteria can help detect and prevent PPO occurrence among older patients.
\end{abstract}


inappropriate prescribing of medications (Barry, 2002; Juurlink et al., 2003; Onder et al., 2002). Most of the published articles were in regard to prescribing medications that should be avoided in these patients. However, data are limited regarding using the screening tools to assess prescribing omissions in this group of patients (Alice Oborne et al., 2003; Batty et al., 2003). This could result from the lack of appropriate screening tools. Researchers developed the Screening Tool to Alert doctors to the Right Treatment (START) criteria for detecting potential prescribing omissions (PPOs) of medications in older adults. Since 2008, the START criteria have been updated and the most recent draft for the updated criteria was made available to the public [START version 2 (START V2)] in 2015 (O'Mahony et al., 2015). Recently, researchers evaluated the prevalence and predictors of the cases of PPO in hospitalized patients and revealed that prescribing is highly prevalent among older hospitalized or community-dwelling patients and its impact on hospitalization (Abu Farha et al., 2018; Bo et al., 2018; Cardwell et al., 2020; Moriarty et al., 2016; Moriarty et al., 2020).

In Arab countries so far, there have been no studies conducted using START V2 on inappropriate prescribing. Therefore, it was of interest to determine the prevalence of PPO cases using START V2 for older patients admitted to a tertiary hospital in Jordan and to assess factors associated with potential prescribing omission according to START V2.

\section{METHOD}

\section{Study site, participants, and ethics}

This study is a prospective audit conducted in two geriatric wards at the Jordan University Hospital (JUH) with a capacity of 600 beds. Since this audit aims to improve clinical practice and carries minimal risks for patients, the need for informed consent was waived by the JUH's IRB Committee. During the study period, 560 consecutive admissions of patients with acute or chronic diseases to the two geriatric wards over 18 months (June 2015 to December 2016) were reviewed for inclusion. Patients were chosen to be included in the present study if they met the following criteria: (1) age $>65$ years and (2) a stay of at least one night in the hospital. Ethical approval for the present study was granted from the JUH Institutional Review Board (Reference no. 20667), and consequently the study was started according to the protocols outlined in the World Medical Association Declaration of Helsinki guideline (World Medical Association, 2013).

\section{START criteria}

START is an explicit criterion that facilitates medication review in multimorbid older patients in most clinical settings designed to detect common and/or important cases of PPOs ${ }^{18}$. In the present study, the application of the second version of START was conducted on concurrent medical diagnostic and prescription information prospectively.

\section{Sample size calculation}

The minimum required sample size as calculated by the Raosoft sample size calculator was 196 participants, assuming a $7 \%$ margin of error and a $50 \%$ prevalence rate with $95 \%$ confidence.

\section{Data collection}

Data, including the standard demographic and medical details, were obtained from clinical and prescription records for 200 patients. START V2 was then applied by the main researcher to identify the cases of PPO. Independent verifications were commenced by a clinical pharmacist. Each new admission to any of the included wards was reviewed by the researcher for fitness for inclusion. The wards were visited regularly for data collection. Clinical records, including medication charts of the included patients, were used as the primary data source and reviewed to gain information about patients. Standard demographic details, primary medical reasons for admission, acute and chronic medical conditions, laboratory results, and medications before admission, current medications, and discharge medications were abstracted from each patient's clinical records and prescription charts. These data were recorded using a predesigned data collection form. Each patient was given a unique anonymous code during the data collection process to preserve anonymity and to facilitate data analysis. Each included patient was followed-up until discharge.

\section{Application of START criteria and identification of PPO cases}

Cases of PPOs were identified by two clinical pharmacists using validated START criteria V2 upon admission, during hospitalization, and on discharge. Each START criterion was applied to each patient by the first clinical pharmacist [Sara AlHabeis (SA)] about his/her medical conditions to ascertain if there were instances of PPO. All identified cases of PPO for each patient were documented in the data collection proforma sheets which were designed to record cases of PPO of medications according to START criteria V2. Details of identified cases of PPO were reported in these sheets as follows: medication associated with each identified case of PPO for each patient and class and description of the identified case of PPO according to START criteria V2 classifications. Independent verification of PPO cases identified by the researcher was undertaken by an associate professor in clinical pharmacy [Abu Hammour KH (KA)]. In case of any discrepancy in the identification of PPOs, the researchers discussed the cases until consensus was reached.

\section{Statistical analysis}

The collected data in the present study were coded and entered into the Statistical Package for Social Science (SPSS) (version 20.0, SPSS Inc., Chicago, Illinois) for statistical analysis. Descriptive analyses (percentages, means, and SD) were used as appropriate to describe the variables of interest. Ratios of all identified cases of $\mathrm{PPO} /$ all prescribed medications for each patient were calculated upon admission, during hospitalization, and on discharge. Logistic regression analysis was used to examine the association between selected demographic and clinical variables and the number of identified cases of PPO for the study sample upon admission, during hospitalization, and on discharge independently. To be considered statistically significant, $p$-values were set a priori at $p<0.05$. 


\section{Outcome measures}

An assessment of the prevalence of PPOs was the main outcome of the present study and was evaluated using START V2 for included patients upon admission, during hospitalization, and on discharge.

\section{RESULTS}

\section{Demographic and clinical characteristics of the study sample}

Between June 2015 and December 2016, 200 patients received medication-use reviews across two geriatric wards. The median age of the patients [interquartile range (IQR)] was 73.0 years (8.0). Around half of them were male (50.5\%). The most common chronic and acute comorbidities in the study population were hypertension, type 2 diabetes mellitus (T2DM), chronic kidney disease (CKD), ischemic heart disease (IHD), and heart failure. The median length of hospitalization (IQR) was 4.0 days (4.0). The median number of the prescribed medications (IQR) was 6.0 (4.0) upon admission, 10 (5.0) during hospitalization, and 7.0 (4.0) on discharge. An overview of the characteristics of the study sample is provided in Table 1.

\section{Prevalence and details of PPO cases identified by START V2}

Application of the START criteria identified 126 cases of PPO upon admission, 134 cases during hospitalization, and 131 cases on discharge. There was inconsiderable variation in the mean number of identified cases of PPO for the study population upon admission, during hospitalization, and on discharge. Using START criteria V2, one or more indicated medications were omitted in more than one-third of the patients upon admission $(40.5 \%)$, during hospitalization $(41.0 \%)$, or on discharge $(39.5 \%)$. The prevalence of identified PPO (95\% CI) was 10.4 (8.7-11.1), 7.0 (5.9-8.1), and 9.5 (8.0-11.0), respectively. Table 2 provides details of the number of medications prescribed for the study population and details of PPO cases during their hospital journey.

\section{Classification of identified cases of PPO}

Vaccines and angiotensin-converting enzyme inhibitors (ACEIs) were the most common drug classes involved in the identified cases of PPOs at different stages of the hospital stay, followed by statins. Vitamin D and calcium supplements, antiplatelets, bisphosphonates, and laxatives were the other drug classes involved in the identified cases of PPOs at the three stages of hospital stay (Fig. 1).

The highest prevalence of the recognized cases of PPO for the study population upon admission, during hospitalization, and on discharge based on START V2 criterion I1 was "seasonal trivalent influenza vaccine annually." This was followed by criterion A6: "ACEIs with systolic heart failure and/or documented coronary artery disease," followed by START criterion A5: "statin therapy with a documented history of coronary, cerebral, or

Table 1. Demographic and clinical characteristics of the patients included in the study $(n=200)$.

\begin{tabular}{|c|c|c|c|}
\hline Variable & Categories & Median (IQR) & $n(\%)$ \\
\hline \multirow[t]{2}{*}{ Gender } & Male & & $101(50.5)$ \\
\hline & Female & & $99(49.5)$ \\
\hline Age (years) & & $73.0(8.0)$ & \\
\hline \multirow[t]{3}{*}{ Marital status } & Married & & $139(69.5)$ \\
\hline & Single & & $3(1.5)$ \\
\hline & Other & & $58(29.0)$ \\
\hline \multirow{5}{*}{$\begin{array}{l}\text { Most commonly encountered } \\
\text { medical conditions }\end{array}$} & Hypertension & & $171(85.5)$ \\
\hline & $\mathrm{T} 2 \mathrm{DM}$ & & $138(69.0)$ \\
\hline & IHD & & $66(33)$ \\
\hline & CKD & & $45(22.5)$ \\
\hline & Heart failure & & $44(22)$ \\
\hline \multirow[t]{4}{*}{ Reason for admission } & Shortness of breath & & $48(24.0)$ \\
\hline & Chest pain & & $25(12.5)$ \\
\hline & Infection with fever & & $24(12.0)$ \\
\hline & Abdominal pain and diarrhea & & $18(9.0)$ \\
\hline Length of stay & & $4.0(4.0)$ & \\
\hline \multirow{3}{*}{$\begin{array}{l}\text { Mean number of prescribed } \\
\text { medications }\end{array}$} & On admission & $6.0(4.0)$ & \\
\hline & During hospitalization & $10(5.0)$ & \\
\hline & On discharge & $7.0(4.0)$ & \\
\hline
\end{tabular}

T2DM: Type 2 diabetes mellitus, CKD: chronic kidney disease, and IHD: ischemic heart disease. 
Table 2. Medication variables, numbers, and ratios of identified cases of PPO for all prescribed medications for the study population at each stage in the hospital journey.

\begin{tabular}{|c|c|c|c|}
\hline Parameter & $\begin{array}{c}\text { Upon } \\
\text { admission }\end{array}$ & $\begin{array}{c}\text { During } \\
\text { hospitalization }\end{array}$ & On discharge \\
\hline \multicolumn{4}{|l|}{ Medication variables } \\
\hline Number of all drugs prescribed & 1,212 & 1,916 & 1,377 \\
\hline Number of drugs prescribed on regular basis (\%) & $1,158(95.5)$ & $1,837(95.9)$ & $1,279(92.9)$ \\
\hline Number of drugs prescribed when required (\%) & $54(4.5)$ & $79(4.1)$ & $98(7.1)$ \\
\hline \multicolumn{4}{|l|}{ Cases of PPO } \\
\hline Total number & 126 & 134 & 131 \\
\hline Median number per patient $( \pm \mathrm{IQR})$ & $0( \pm 1.0)$ & $0( \pm 1.0)$ & $0( \pm 1.0)$ \\
\hline Prevalence of PPO $[96 \% \mathrm{CI}]$ & $10.4(8.7-12.1)$ & $7.0(5.9-8.1)$ & $9.5(8.0-11.0)$ \\
\hline \multicolumn{4}{|l|}{ Number of PPO cases per patient (\%) } \\
\hline 0 & $119(59.5)$ & $118(59.0)$ & $121(60.5)$ \\
\hline 1 & $49(24.5)$ & $46(23.0)$ & $42(21.0)$ \\
\hline 2 & $23(11.5)$ & $24(12.0)$ & $26(13.0)$ \\
\hline 3 & $5(2.5)$ & $8(4.0)$ & $7(3.5)$ \\
\hline 4 or more & $4(2.0)$ & $4(2.0)$ & $4(2.0)$ \\
\hline
\end{tabular}

IQR: interquartile range and 95\% CI: 95\% confidence interval.

peripheral vascular disease, unless the patient's status is end-oflife or age is $>85$ years" (Table 3 ).

\section{Associated factors with increased risk of potential prescribing errors}

The results of the logistic regression analysis showed that the higher number of medical conditions was associated with increased risk of PPO occurrence upon admission, during hospitalization, and on discharge $(p$ value $<0.05)$, while none of the other studied factors showed a significant association with PPO occurrence, as shown in Table 4.

\section{DISCUSSION}

Recent studies in Jordan showed that drug prescribing omission was one of the major errors detected in implementing the medication reconciliation process in different settings (Abu Farha et al., 2018; Abu Hammour and Abdel Jalil, 2016; Salameh et al., 2019). Nonetheless, this is the first study using validated START V2 criteria to identify the rate of omissions of appropriate medications in older patients in Arab countries. The results indicated high prevalence of identified cases of PPOs among the study population during their hospital stay.

The application of the START V2 criteria in the present study revealed that over one-third of the patients had one or more appropriate medications omitted during their hospital stay $(40.5 \%$ upon admission, $41.0 \%$ during hospitalization, and $39.5 \%$ on discharge). START V2 criteria have also been seen in the practice in a few studies conducted in European countries (Lang et al., 2010; Miquel et al., 2010; Ryan et al., 2009). Ryan et al. (2009) reported that PPOs were identified in $22.7 \%$ of Irish patients (Ryan et al., 2009). However, other studies showed even higher percentages of patients exposed to PPOs. Miquel et al. (2010) reported that 54\% of nursing home residents were exposed to PPOs (Miquel et al.,
2010). Lang et al. (2010) noted that $65 \%$ of hospitalized mentally ill older patients also experienced PPOs (Lang et al., 2010).

Generally speaking, omissions in this special group of patients could be related to the desire of healthcare professionals to avoid polypharmacy. This is due to the lack of clear-cut evidence of the efficacy of polypharmacy in frail patients aged 80 years or more or to avoid the possible side effects of such medications. As for vaccinations, a possible reason for omissions could be related to low awareness of the importance of vaccines (Williams et al., 2016).

Classifying the identified cases of PPOs into drug classes in this study demonstrated that the most common drug classes associated with identified PPO cases involved vaccines, ACEIs, antiplatelets, statins, and vitamin D/calcium supplements. The findings of the present study were similar to results that were reported by other published studies (Gallagher et al., 2011; Frankenthal et al., 2013; Liu et al., 2012; Ryan et al., 2009).

It is interesting to note that there were slight variations in the percentages of patients exposed to one or two or more cases of PPOs over their hospital journey. Attributable to the fact is that if patients had prescription omissions upon admission, then the probability of recognizing these omissions is minimal. As a result, patients may be hospitalized and discharged with the same case of PPO.

The most common factors associated with identified cases of PPOs in the previous studies were the number of comorbidities. Lang et al. (2010) reported that identified cases of PPOs were relatively common among older patients discharged from the hospital to the community and those cases were found to be associated with a high number of comorbidities (Lang et al., 2010).

Regression analysis showed no association was found between PPOs occurrence and the number of medications 


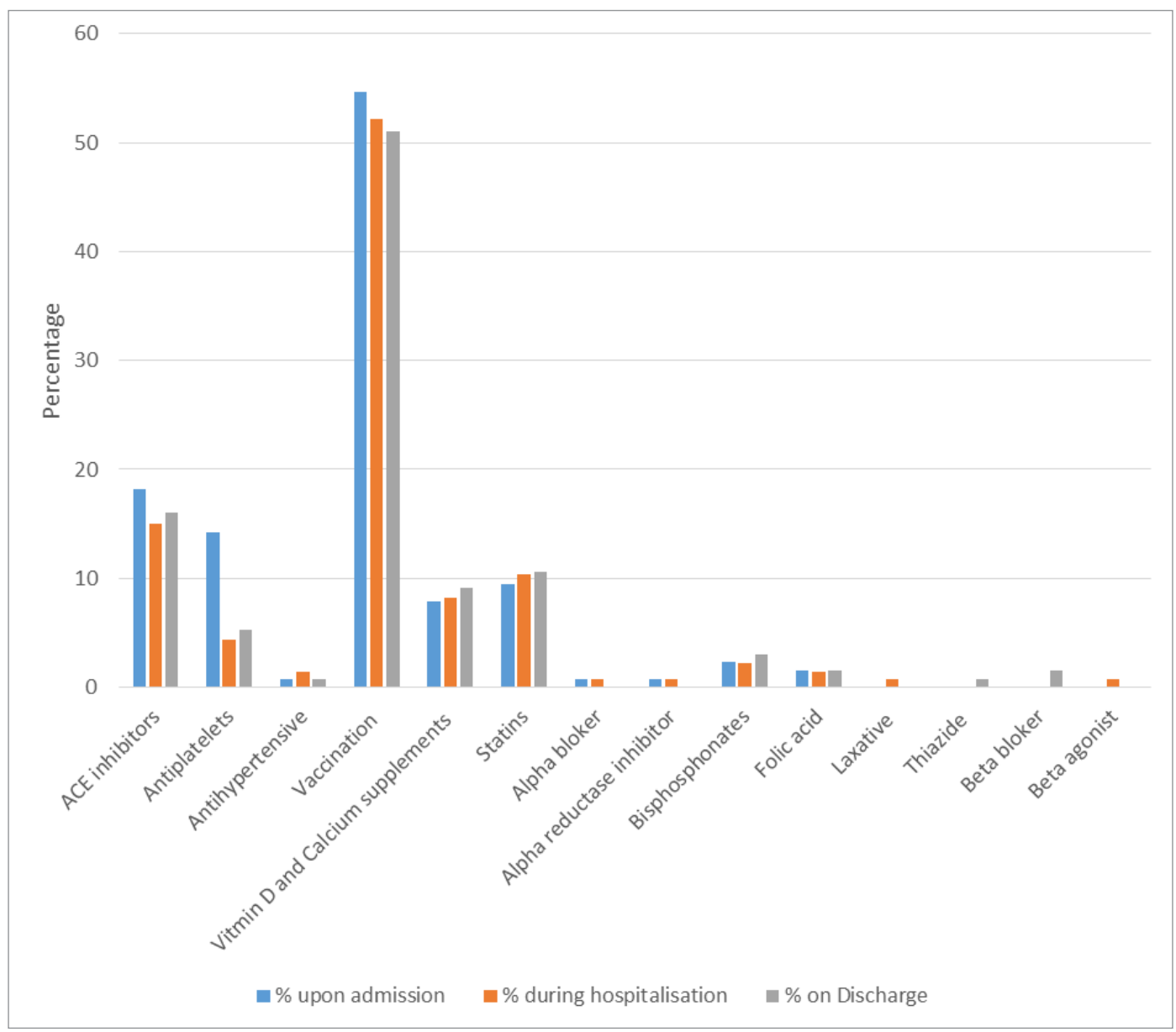

Figure 1. Drug classes involved in the identified cases of PPOs at different stages of the hospital stay.

Table 3. Prevalence of potentially inappropriate prescribing medication among the study population by individual START criteria description.

\begin{tabular}{|c|c|c|c|}
\hline START criterion & $\begin{array}{l}\text { Upon admission } \\
\qquad N(\%)\end{array}$ & $\begin{array}{c}\text { During } \\
\text { hospitalization } \\
N(\%)\end{array}$ & $\begin{array}{c}\text { On discharge } N \\
(\%)\end{array}$ \\
\hline $\begin{array}{l}\text { I. Seasonal trivalent influenza vaccine annually, Pneumococcal vaccine at } \\
\text { least once after age } 65 \text { according to national guidelines }\end{array}$ & $69(54.8)$ & $69(51.5)$ & $68(51.9)$ \\
\hline $\begin{array}{l}\text { A6. ACE inhibitor with systolic heart failure and/or documented coronary } \\
\text { artery disease }\end{array}$ & $19(15.10)$ & $19(14.2)$ & $17(13.0)$ \\
\hline $\begin{array}{l}\text { A5. Statin therapy with a documented history of coronary, cerebral, or } \\
\text { peripheral vascular disease, unless the patient's status is end-of-life or age } \\
\text { is }>85 \text { years }\end{array}$ & $11(8.7)$ & $12(9.0)$ & $13(9.9)$ \\
\hline $\begin{array}{l}\text { E5. Vitamin D supplements in older people who are housebound or } \\
\text { experiencing falls or with osteopenia (Bone Mineral Density T-score is }> \\
-1.0 \text { but }<-2.5 \text { in multiple sites) }\end{array}$ & $9(7.1)$ & $9(6.7)$ & $6(4.6)$ \\
\hline $\begin{array}{l}\text { F1. ACE inhibitor or Angiotensin Receptor Blocker (if intolerant of } \\
\text { ACE inhibitor) in diabetes with evidence of renal disease i.e., dipstick } \\
\text { proteinuria or microalbuminuria ( }>30 \mathrm{mg} / 24 \text { hours) with or without serum } \\
\text { biochemical renal impairment }\end{array}$ & $5(4.0)$ & $5(3.7)$ & $5(3.8)$ \\
\hline $\begin{array}{l}\text { A2. Aspirin ( } 75-160 \mathrm{mg} \text { once daily) in the presence of chronic atrial } \\
\text { fibrillation, where Vitamin } \mathrm{K} \text { antagonists or direct thrombin inhibitors or } \\
\text { factor Xa inhibitors are contraindicated }\end{array}$ & $4(3.2)$ & $5(3.7)$ & $4(3.1)$ \\
\hline $\begin{array}{l}\text { E3. Vitamin D and calcium supplement in patients with known } \\
\text { osteoporosis and/or previous fragility fracture(s) and/or (Bone Mineral } \\
\text { Density T-scores more than }-2.5 \text { in multiple sites) }\end{array}$ & $1(0.7)$ & $2(1.5)$ & $6(4.6)$ \\
\hline Others & $8(6.3)$ & $12(9.0)$ & $12(9.2)$ \\
\hline
\end{tabular}


Table 4. Logistic regression analysis of factors affecting the occurrence of PPO upon admission, during hospitalization, and on discharge.

\begin{tabular}{|c|c|c|c|c|c|c|}
\hline \multirow[t]{5}{*}{ Variables } & \multirow{2}{*}{\multicolumn{6}{|c|}{$\begin{array}{c}\text { Dependent variable: PPO occurrence } \\
\text { 0: no, 1: yes }\end{array}$}} \\
\hline & & & & & & \\
\hline & \multirow{2}{*}{\multicolumn{2}{|c|}{$\begin{array}{c}\text { Upon } \\
\text { admission }\end{array}$}} & \multirow{2}{*}{\multicolumn{2}{|c|}{ During hospitalization }} & \multirow{2}{*}{\multicolumn{2}{|c|}{$\begin{array}{c}\text { Upon } \\
\text { discharge }\end{array}$}} \\
\hline & & & & & & \\
\hline & OR & $p$ value & OR & $p$ value & OR & $p$ value \\
\hline Age & 0.985 & 0.498 & 0.983 & 0.428 & 0.990 & 0.665 \\
\hline \multicolumn{7}{|l|}{ Gender } \\
\hline Male & Reference & & Reference & & Reference & \\
\hline Female & 0.798 & 0.438 & 0.903 & 0.737 & 1.099 & 0.753 \\
\hline Number of prescribed medications & 1.059 & 0.162 & 1.019 & 0.643 & 1.065 & 0.142 \\
\hline Number of medical conditions & 1.242 & $0.021 *$ & 1.215 & $0.037^{*}$ & 1.230 & $0.033^{*}$ \\
\hline
\end{tabular}

*Significant at 0.05 significance level.

prescribed in this study. Similar to the present study findings, Ryan et al. (2009) reported no significant relationship between the numbers of medications prescribed and identified cases of PPOs (Ryan et al., 2009). On the contrary, Kuijpers et al. (2008) reported that the occurrence of PPO cases was related to the number of medications prescribed.

This difference could be due to variations in the study population, the setting, and the assessment method. On the other hand, a significant association was found between the occurrence of PPOs and the number of medical conditions. A possible reason is that in older people with comorbidities healthcare providers set individual priorities to management instead of treating all diseases and conditions (Blanco-Reina et al., 2015; Gorup and Šter, 2017). Surprisingly, other researchers claimed that underuse also had strong associations with mortality and hospitalization (BlancoReina et al., 2015). Therefore, future research in other larger study populations is required to explain these differences, confirm these results, and show their clinical impact.

It is worth mentioning the strengths and limitations of this study. One strength is that the cases of PPOs were reported according to a validated instrument. However, the number of reported cases of PPOs may have been underestimated as a result of possible incomplete documentation. Additionally, overestimation is possible as a result of lacking the information on conditions for which therapeutic omissions could be appropriate. Furthermore, data were collected for older patients who were admitted to one hospital only. Therefore, results cannot be generalized to other patients and these omissions could be considered potential or probable omissions, as the treatment of patients may be subject to physician's judgment.

The START tool has been reported to be a user-friendly tool that can identify cases of inappropriate omissions. Utilizing this tool, the results of the present study revealed high prevalence of omission of indicated appropriate medications in acutely ill hospitalized older patients, particularly in regard to vaccines and cardiovascular drugs. An improvement of quality of prescription for older patients was also highlighted by the results of the present study in addition to the need to revise the management plan of disease for polymedicated older patients using these criteria, depending on the conclusions of the previous studies that showed that the application of START criteria significantly improves medication appropriateness and the quality of life. This present study has established baseline research in a teaching hospital to use specific tools like START criteria to detect the cases of PPOs and ultimately improve the quality of prescription for older patients.

Future research examining the impact of softwaregenerated START criteria on drug-related hospitalizations and quality of life is needed for implementing medication prescription in day-to-day practice, bearing in mind that such criteria cannot replace clinical judgment. A recent first clinical trial to examine the effectiveness of a software intervention on incidental adverse drug reactions and associated healthcare costs during hospitalization for older patients with polypharmacy and comorbidities is ongoing (Lavan et al., 2019). On the contrary, other researchers claimed that the application of such software did not reduce adverse drug reaction incidence during hospitalization (O'Mahony et al., 2020).

\section{FUNDING}

This research did not receive any grant from funding agencies in the public, commercial, or not-for-profit sectors.

\section{AUTHOR CONTRIBUTIONS}

All authors made substantial contributions to conception and design, acquisition of data, or analysis and interpretation of data; took part in drafting the article or revising it critically for important intellectual content; agreed to submit to the current journal; gave final approval of the version to be published; and agree to be accountable for all aspects of the work. All the authors are eligible to be an author as per the international committee of medical journal editors (ICMJE) requirements/guidelines.

\section{CONFLICTS OF INTEREST}

The authors report no financial or any other conflicts of interest in this work.

\section{PUBLISHER'S NOTE}

This journal remains neutral with regard to jurisdictional claims in published institutional affiliation. 


\section{REFERENCES}

Abu Farha R, Abu Hammour K, Al-Jamei S, AlQudah R, Zawiah M. The prevalence and clinical seriousness of medication discrepancies identified upon hospital admission of pediatric patients. , 2018; 18(1):966.

Abu Hammour K, Abdel Jalil M. Medication errors in voluntary reported incidents at a Jordanian hospital. J Med J, 2016; 50(2):87-96.

Alice Oborne C, Hooper R, Swift CG, Jackson SH. Explicit, evidence-based criteria to assess the quality of prescribing to elderly nursing home residents. Age Ageing, 2003; 32(1):102-8.

Barry M. Drug expenditure in Ireland 1991-2001. Ir Med J, 2002; 95(10):294.

Batty GM, Grant RL, Aggarwal R, Lowe D, Potter JM, Pearson MG, Jackson SH. Using prescribing indicators to measure the quality of prescribing to elderly medical in-patients. Age Ageing, 2003; 32(3):292-8.

Blanco-Reina E, Ariza-Zafra G, Ocaña-Riola R, León-Ortíz M,

Bellido-Estévez I. Optimizing elderly pharmacotherapy: polypharmacy vs. undertreatment. Are these two concepts related? Eur J Clin Pharmacol, 2015; 71(2):199-207.

Bo M, Gibello M, Brunetti E, Boietti E, Sappa M, Falcone Y, Aurucci M, Iacovino M, Fonte G, Cappa G. Prevalence and predictors of inappropriate prescribing according to the Screening Tool of Older People's Prescriptions and Screening Tool to Alert to Right Treatment version 2 criteria in older patients discharged from geriatric and internal medicine wards: a prospective observational multicenter study. Geriatr Gerontol Int, 2018; 19:5-11.

Cardwell K, Kerse N, Hughes CM, Teh R, Moyes SA, Menzies O, Rolleston A, Broad JB, Ryan C. Does potentially inappropriate prescribing predict an increased risk of admission to hospital and mortality? A longitudinal study of the 'oldest old'. BMC Geriatr, 2020;20(1):28.

Cheragi MA, Manoocheri H, Mohammadnejad E, Ehsani SR. Types and causes of medication errors from nurse's viewpoint. Iran J Nurs Midwifery Res, 2013; 18(3):228.

Frankenthal D, Lerman Y, Kalendaryev E, Lerman Y. Potentially inappropriate prescribing among older residents in a geriatric hospital in Israel. Int J Clin Pharm, 2013; 35(5):677-82.

Gallagher P, Lang PO, Cherubini A, Topinková E, CruzJentoft A, Errasquín BM, Mádlová P, Gasperini B, Baeyens H, Baeyens JP. Prevalence of potentially inappropriate prescribing in an acutely ill population of older patients admitted to six European hospitals. Eur J Clin Pharmacol, 2011; 67(11):1175.

Gorup EC, Šter MP. Number of medications or number of diseases: what influences underprescribing? Eur J Clin Pharmacol, 2017; 73(12):1673-9.

Juurlink DN, Mamdani M, Kopp A, Laupacis A, Redelmeier DA. Drug-drug interactions among elderly patients hospitalized for drug toxicity. JAMA, 2003; 289(13):1652-8.

Kothari D, Gupta S, Sharma C, Kothari S. Medication error in anaesthesia and critical care: a cause for concern. Indian J Anaesth, 2010; 54(3):187.

Kuijpers MA, Van Marum RJ, Egberts AC, Jansen PA, Group OS. Relationship between polypharmacy and underprescribing. Br J Clin Pharmacol, 2008; 65(1):130-3.

Lang PO, Hasso Y, Dramé M, Vogt-Ferrier N, Prudent M, Gold G, Pierre Michel J. Potentially inappropriate prescribing including underuse amongst older patients with cognitive or psychiatric co-morbidities. Age Ageing, 2010; 39(3):373-81.

Lavan AH, O'Mahony D, Gallagher P, Fordham R, Flanagan E, Dahly D, Byrne S, Petrovic M, Gudmundsson A, Samuelsson O, Cherubini A, J Cruz-Jentoft A, Soiza RL, Eustace JA. The effect of SENATOR (software engine for the assessment and optimisation of drug and non-drug therapy in older persons) on incident adverse drug reactions (ADRs) in an older hospital cohort - trial protocol. BMC Geriatr, 2019; 19(1):40.

Liu CL, Peng LN, Chen YT, Lin MH, Liu LK, Chen LK. Potentially inappropriate prescribing (IP) for elderly medical inpatients in Taiwan: a hospital-based study. Arch Gerontol Geriatr, 2012; 55(1):148-51.
Miquel MC, Cuervo MS, Silveira ED, Machuca IS, GonzálezBlazquez S, Errasquin BM, Cruz-Jentoft A. Potentially inappropriate drug prescription in older subjects across health care settings. Eur Geriatr Med, 2010; 1(1):9-14.

Moriarty F, Bennett K, Cahir C, Kenny RA, Fahey T. Potentially inappropriate prescribing according to STOPP and START and adverse outcomes in community-dwelling older people: a prospective cohort study. Br J Clin Pharmacol, 2016; 82(3):849-57.

Moriarty F, Bennett K, Kenny RA, Fahey T, Cahir C. Comparing potentially inappropriate prescribing tools and their association with patient outcomes. J Am Geriatr Soc, 2020; 68(3):526-34.

Mrayyan MT, Al-Atiyyat N. Medication errors in universityaffiliated teaching hospitals as compared to non-university-affiliated teaching hospitals in Jordan. Nurs Forum, 2011; 46(4):206-17.

NICE. Medicines optimisation: the safe and effective use of medicines to enable the best possible outcomes. National Institute for Health and Care Excellence, Manchester, UK, 2015.

O’Mahony D, Gudmundsson A, Soiza RL, Petrovic M, Jose Cruz-Jentoft A, Cherubini A, Fordham R, Byrne S, Dahly D, Gallagher P, Lavan A, Curtin D, Dalton K, Cullinan S, Flanagan E, Shiely F, Samuelsson O, Sverrisdottir A, Subbarayan S, Vandaele L, Meireson E, MonteroErrasquin B, Rexach-Cano A, Correa Perez A, Lozano-Montoya I, VélezDíaz-Pallarés M, Cerenzia A, Corradi S, Soledad Cotorruelo Ferreiro M, Dimitri F, Marinelli P, Martelli G, Fong Soe Khioe R, Eustace J. Prevention of adverse drug reactions in hospitalized older patients with multi-morbidity and polypharmacy: the SENATOR* randomized controlled clinical trial Age Ageing, 2020; 49(4):605-14

O'Mahony D, O'Sullivan D, Byrne S, O'Connor MN, Ryan C, Gallagher P. STOPP/START criteria for potentially inappropriate prescribing in older people: version 2. Age Ageing, 2015; 44(2):213-8.

Onder G, Pedone C, Landi F, Cesari M, Della Vedova C, Bernabei R, Gambassi G. Adverse drug reactions as cause of hospital admissions: results from the Italian group of pharmacoepidemiology in the elderly (GIFA). J Am Geriatr Soc, 2002; 50(12):1962-8.

Ryan C, O'Mahony D, Kennedy J, Weedle P, Byrne S. Potentially inappropriate prescribing in an Irish elderly population in primary care. Eur J Clin Pharmacol, 2009; 68(6):936-47.

Salameh LK, Abu Farha RK, Abu Hammour KM, Basheti IA. Impact of pharmacist's directed medication reconciliation on reducing medication discrepancies during transition of care in hospital setting. J Pharm Health Serv Res, 2019; 10(1):149-56.

Williams WW, Lu PJ, O’Halloran A, Kim DK, Grohskopf LA, Pilishvili T, Skoff TH, Nelson NP, Harpaz R, Markowitz LE. Surveillance of vaccination coverage among adult populations-United States, 2014 MMWR Surveill Summ, 2016; 65(1):1-36.

World Medical Association. World medical association declaration of helsinki: ethical principles for medical research involving human subjects. JAMA, 2013; 310(20):2191-4.

How to cite this article:

Hammour KA, Abdeljalil M, Farha RA, Alhabeis S, Manaseer Q, AbuMoghli S. Potential prescribing omissions of medications in older adults based on START version 2 criteria in a tertiary Jordanian teaching hospital. J Appl Pharm Sci, 2021; 11(11):046-052. 